\title{
Prognostic relevance of persistence of myelin oligodendrocyte glycoprotein antibody in pediatric acute disseminated encephalomyelitis
}

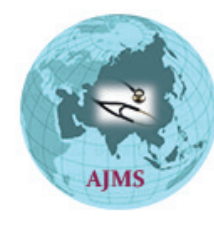

\author{
Asish Banerjee ${ }^{1}$, Meenakshi Mitra ${ }^{2}$ \\ ${ }^{1}$ Associate Professor, ${ }^{2}$ Assistant Professor, Department of Paediatrics, IQ City Medical College, West Bengal University \\ of Health Sciences, Durgapur, West Bengal, India
}

Background: Myelin oligodendrocyte glycoprotein (MOG) antibody plays a significant role in demyelination in pediatric acute disseminated encephalomyelitis (ADEM). Aims and Objectives: To assess the prognostic relevance of persistence of MOG antibody in pediatric ADEM. Materials and Methods: A prospective observational study was conducted over a period of 3 years. Data were collected from Department of Pediatrics of a tertiary care hospital in Durgapur. Neurological examination findings, magnetic resonance imaging brain and spinal cord, electroencephalogram findings, and MOG antibody titer were noted. All patients were followed up for 1 year. MOG Antibody titer was repeated after 6 months of the first episode of demyelination. Data gathered from the patients was documented. Data analysis was performed using fisher's exact test on graph pad $2 \times 2$ contingency table. $P<0.05$ was considered as statistically significant. Results: Fifty-three children were diagnosed with ADEM. Among these, 27 children were MOG antibody-positive (51\%). One child expired and five children were lost to follow up. Forty-seven children were followed up for 1 year. MOG antibody titer was sent at the time of diagnosis and 6 months after first episode of demyelination. Persistently positive MOG antibody (positive at 6 months after $1^{\text {st }}$ episode of demyelination) was significantly associated with the development of multiphasic disseminated encephalomyelitis (MDEM) $(P<0.0001)$, epilepsy $(P=0.0176)$, steroid dependency $(P<0.0001)$, persistent gait disturbance $(P=0.0026)$, but not with the development of Multiple Sclerosis $(P=1.000)$. Conclusion: Persistently positive MOG Antibody was significantly associated with development of MDEM, epilepsy, persistent gait disturbance, and steroid dependency.

Key words: Acute disseminated encephalomyelitis; Multiphasic disseminated encephalomyelitis; Myelin oligodendrocyte glycoprotein antibody
Access this article online

Website:

http://nepjol.info/index.php/AJMS

DOI: 10.3126/ajms.v13i3.41220

E-ISSN: 2091-0576

P-ISSN: 2467-9100

Copyright (c) 2022 Asian Journal of Medical Sciences

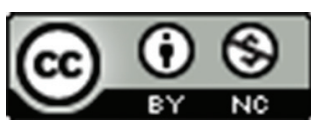

This work is licensed under a Creative Commons Attribution-NonCommercial 4.0 International License.

\section{INTRODUCTION}

Acute disseminated encephalomyelitis (ADEM) is inflammatory demyelinating event presenting with an acute multifocal neurologic deficit, accompanied by encephalopathy and abnormal neuroimaging. ${ }^{1-3}$ The predicted occurrence of ADEM in children ranges $0.2-0.4 / 100,000 .^{4-6}$ ADEM is usually monophasic but recurrence can occur. ${ }^{7}$ New episode of ADEM 3 months or more after the initial episode that can be associated with new or remerging prior clinical and magnetic resonance imaging (MRI) finding is termed as multiphasic disseminated encephalomyelitis (MDEM) ${ }^{8-10}$ Predicting the possibility of multiphasic course after first demyelinating episode is a challenge in clinical practice, and has important clinical significance. ${ }^{11}$ Early detection of patients with a first demyelinating episode and are at risk for develop multiphasic ADEM in future, allows disease-modifying therapeutic agents to be started early and subsequently preservation of brain function. ${ }^{12,13}$

Basic pathogenesis ADEM is immune-mediated injury on the white matter insulating the brain, optic nerve, and spinal cord..$^{14,15}$ There is one immunoglobulin (Ig) G 
antibody, myelin oligodendrocyte glycoprotein (MOG) antibody which plays a vital role in demyelination, ${ }^{16-20} \mathrm{MOG}$ antibody-associated diseases are a recently recognized set of disorders, which include ADEM presentations, among other phenotypes. ${ }^{21}$ Thus, we undertook this study to determine prognostic relevance of persistence of MOG antibody in Pediatric ADEM.

\section{Aims and objectives}

The objective of the study is to assess the prognostic relevance of persistence of MOG antibody in Paediatric ADEM.

\section{MATERIALS AND METHODS}

This prospective observational study was conducted over a period of 3 years (January 2018-December 2020) by collecting data from outpatient and inpatient department of pediatrics of IQ City medical college and hospital, Durgapur, West Bengal. Children of 2-18 years of age diagnosed with ADEM by the international Paediatric Multiple Sclerosis (MS) Study Group diagnostic criteria (both clinical and neuroimaging) ${ }^{22}$ were included in the study. Known or diagnosed case of genetically determined leukodystrophies, infective, metabolic, and toxic encephalitis were excluded from the study. Clearance was collected from the Institutional Ethical committee. Informed consent was obtained from all the parents of children included in the study. Age, sex, age at the time of diagnosis, detailed neurological examination findings, and cerebrospinal fluid (CSF) findings were recorded. MRI brain, orbit, and spine with contrast and electroencephalogram findings were also noted. In appropriate clinic-radiological scenarios, CSF oligoclonal bands, Serum antibodies to the astrocyte water channel protein aquaporin-4 (AQP4-Ab), visually-evoked response were also done and findings were recorded. MOG antibody titer was sent at the time of diagnosis. MOG antibody $\operatorname{IgG}$ was detected in serum, using a cellbased assay (indirect fluorescence test) and employing fulllength human MOG as the target antigen using a cutoff of $\geq 1: 160 .{ }^{22}$ All patients underwent follow-up for 1 year and relevant data was recorded. MOG Antibody titer was sent after 6 months after $1^{\text {st }}$ episode of demyelination. The outcome of these children was classified into three groups - monophasic ADEM, MDEM ${ }^{8-10}$ and death. Epilepsy is defined as having two or more unprovoked seizures. Gait disturbances are described as any deviations from normal walking or gait. Neurological symptoms appearing within 3 months of the first episode of ADEM or within 4 weeks of treatment after a complete remission in those patients who had received $<6$ weeks of oral steroids was considered as steroid dependency. 23,24 .

Data analysis was performed using fisher's exact test on graph pad $2 \times 2$ contingency table. $\mathrm{P}<0.05$ was considered as statistically significant.

\section{RESULTS}

Fifty-three children were diagnosed with ADEM over a period of 3 years. The baseline characteristic of study population at the time of the first diagnosis is depicted in Table 1.

Among them, 27 children were MOG antibody-positive $(51 \%)$ at the onset of demyelination.One patient $(2 \%)$ had serum AQP4-Ab antibody positive. One patient expired and five patients were lost to follow-up. Forty-

\begin{tabular}{|c|c|c|c|c|c|c|}
\hline \multicolumn{7}{|l|}{ Demography } \\
\hline \multirow{3}{*}{$\begin{array}{l}\text { Feature } \\
\text { Sex }\end{array}$} & \multicolumn{2}{|c|}{$\begin{array}{l}\text { Preschool ( } 2-5 \text { years) } \\
(n=19 ; 35 \%)\end{array}$} & \multicolumn{2}{|c|}{$\begin{array}{c}\text { School }(5-10 \text { years }) \\
(n=24 ; 45 \%)\end{array}$} & \multicolumn{2}{|c|}{$\begin{array}{l}\text { Adolescents (11-18) } \\
\quad(n=10 ; 20 \%)\end{array}$} \\
\hline & Male & Female & Male & Female & Male & Female \\
\hline & 73 & 27 & 69 & 31 & 65 & 35 \\
\hline \multicolumn{7}{|l|}{ Clinical features } \\
\hline Encephalopathy & \multicolumn{2}{|c|}{100} & \multicolumn{2}{|c|}{100} & \multicolumn{2}{|c|}{100} \\
\hline Seizures & \multicolumn{2}{|c|}{52} & \multicolumn{2}{|c|}{46} & \multicolumn{2}{|c|}{41} \\
\hline Gait disturbance & \multicolumn{2}{|c|}{42} & \multicolumn{2}{|c|}{33} & \multicolumn{2}{|c|}{47} \\
\hline Hemiparesis & \multicolumn{2}{|c|}{31} & \multicolumn{2}{|c|}{41} & \multicolumn{2}{|c|}{34} \\
\hline Visual loss & \multicolumn{2}{|c|}{0} & \multicolumn{2}{|c|}{4} & \multicolumn{2}{|c|}{10} \\
\hline Cranial neuropathy & \multicolumn{2}{|c|}{21} & \multicolumn{2}{|c|}{18} & \multicolumn{2}{|c|}{12} \\
\hline Bowel bladder dysfunction & \multicolumn{2}{|c|}{9} & \multicolumn{2}{|c|}{11} & \multicolumn{2}{|c|}{5} \\
\hline Sensory deficit & \multicolumn{2}{|c|}{4} & \multicolumn{2}{|c|}{6} & \multicolumn{2}{|c|}{2} \\
\hline \multicolumn{7}{|l|}{ MRI findings } \\
\hline Cerebral hemisphere demyelination & \multicolumn{2}{|c|}{100} & \multicolumn{2}{|c|}{100} & \multicolumn{2}{|c|}{100} \\
\hline Cerebellum and brain stem demyelination & \multicolumn{2}{|c|}{67} & \multicolumn{2}{|c|}{41} & \multicolumn{2}{|c|}{37} \\
\hline Spinal cord demyelination & & & & & & \\
\hline MOG positivity & & & & & & \\
\hline
\end{tabular}


seven patients underwent follow-up for 1 year. MOG Antibody titer was sent after 6 months after $1^{\text {st }}$ episode of demyelination. Among these 47 patients, 25 patients (53\%) were MOG Antibody positive at $1^{\text {st }}$ episode of demyelination and rest $22(47 \%)$ were negative. After 6 months among 22 patients who were initially MOG Antibody negative, two patients (9\%) were newly MOG Antibody positive. Among 25 patients who were initially MOG Antibody positive, 17 patients (68\%) were persistently positive after 6 months, and rest eight patients $(32 \%)$ were MOG Antibody negative. During follow-up among 47 patients 22 patients (47\%) developed MDEM, 3 patients $(6 \%)$ developed MS, rest 22 patients (47\%) had complete recovery. Among 47 patients during follow-up, 11 patients $(23 \%)$ developed epilepsy, 16 patients $(34 \%)$ developed steroid dependency, and 13 patients $(27 \%)$ developed persistent gait disturbances. During 1 year follow-up among 22 patients of MDEM, 18 patients $(81 \%)$ had one episode of recurrence and four patients $(19 \%)$ had two episodes of recurrence. Persistently positive MOG Antibody (positive after 6 months after $1^{\text {st }}$ episode of demyelination) was significantly associated with development of MDEM $(\mathrm{P}<0.0001)$ (Table 2), persistence of Epilepsy ( $\mathrm{P}=0.0176)$ (Table 3), steroid dependency $(\mathrm{P}<0.0001)$ (Table 4$)$, gait disturbance $(\mathrm{P}=0.0026)$ (Table 5), but not with development of MS $(\mathrm{P}=1.000)$ (Table 6).

\section{DISCUSSION}

At the first episode of ADEM, antibodies to MOG have been identified in $30-50 \%{ }^{16,25,26}$ of children in various studies. This is comparable to the MOG Antibody positivity (51\%) of our study.

A recurrence rate of $18-24 \%$ has been described in the literature. ${ }^{27,28}$ The recurrence rate is higher in our study at
47\%. An episode of ADEM is known to be precipitated by a prior viral infection. In the time period, the study was conducted, there was a peak in covid 19 infections. Although it has not been proved, the Covid-19 virus may be responsible for the increase in demyelination episodes, like other respiratory viruses. There was also a surge in influenza vaccinations in the same time period as it was thought to be beneficial during the covid pandemic. This could be another possible cause.

Our present study indicates that persistently positive MOG Antibody (positive after 6 months after $1^{\text {st }}$ episode of demyelination) is significantly associated with the development of MDEM, Epilepsy, steroid dependency, and persistent gait disturbance. The increased chance of relapse seen in persons with continued MOG antibody positivity has vital clinical significance. Information concerning the treatment of ADEM with anti-MOG antibody is complicated and limited both in regard to largescale studies and long-term follow-up. ${ }^{29}$ Glucocorticoid is the treatment of choice in patients with an acute demyelinating episode and anti-MOG antibody positive. ${ }^{12}$ Interestingly, after dose reduction and cessation of steroids these patients are at risk of relapses. ${ }^{13}$ For this reason, prolonged and slow steroid tapers are often advised after an initial anti-MOG-associated demyelinating episode. However, it remains unclear whether all MOG antibody-positive ADEM patients will require long-term treatment or not. Some research found a reduction of relapse rate with various immunomodulators such as azathioprine, methotrexate, rituximab, and mycophenolate if total duration of treatment is more than 3 months. ${ }^{13,30}$ Another recent study showed the advantages of intravenous Igs on reduction of annualized relapse rate in children with relapsing MOG antibody-positive ADEM. ${ }^{12}$ It remains to be identified whether the disease course (i.e., single attack versus further relapses) or higher

\section{Table 2: Distribution of persistent MOG positivity with development of MDEM}

\begin{tabular}{lccc}
\hline $\begin{array}{l}\text { MOG titer (6 months after } \mathbf{1}^{\text {st }} \\
\text { episode of demyelination) }\end{array}$ & $\begin{array}{c}\text { MDEM developed } \\
\text { during follow-up (\%) }\end{array}$ & $\begin{array}{c}\text { MDEM not developed } \\
\text { during follow-up (\%) }\end{array}$ & Total \\
\hline Positive & $16(72)$ & $3(12)$ & 19 \\
Negative & $6(28)$ & $22(88)$ & 28 \\
Total & 22 & 25 & \\
\hline
\end{tabular}

P<0.0001, MOG: Myelin oligodendrocyte glycoprotein, MDEM: Multiphasic disseminated encephalomyelitis

Table 3: Distribution of persistent MOG positivity with development of epilepsy

\begin{tabular}{|c|c|c|c|c|c|}
\hline $\begin{array}{l}\text { MOG titer (6 months after } 1^{\text {st }} \\
\text { episode of demyelination) }\end{array}$ & $\begin{array}{l}\text { Epilepsy persisted } \\
\text { during followup (\%) }\end{array}$ & $\begin{array}{l}\text { Epilepsy not developed } \\
\text { during follow-up (\%) }\end{array}$ & Total & $\begin{array}{l}\text { MDEM not developed } \\
\text { during follow-up (\%) }\end{array}$ & Total \\
\hline Positive & $8(72)$ & $11(30)$ & 19 & $3(12)$ & 19 \\
\hline Negative & $3(28)$ & $25(70)$ & 28 & $22(88)$ & 28 \\
\hline Total & 11 & 36 & & 25 & \\
\hline
\end{tabular}

$\mathrm{P}=0.0176$, MOG: Myelin oligodendrocyte glycoprotein 
Table 4: Distribution of persistent MOG positivity with development of steroid dependency

\begin{tabular}{lccc}
$\begin{array}{l}\text { MOG titer (6 months after } \mathbf{1}^{\text {st }} \\
\text { episode of demyelination) }\end{array}$ & $\begin{array}{c}\text { Steroid dependency persisted } \\
\text { during follow-up (\%) }\end{array}$ & $\begin{array}{c}\text { Steroid dependency not } \\
\text { developed during follow-up (\%) }\end{array}$ & $\begin{array}{c}\text { Total } \\
\text { Positive }\end{array}$ \\
Negative & $14(87)$ & $5(16)$ & 19 \\
Total & $2(13)$ & $26(84)$ & 28 \\
\hline
\end{tabular}

$\mathrm{P}<0.0001$, MOG: Myelin oligodendrocyte glycoprotein

\section{Table 5: Distribution of persistent MOG positivity with development of persistent of gait disturbance}

\begin{tabular}{lccc}
\hline $\begin{array}{l}\text { MOG titer (6 months after 1st } \\
\text { episode of demyelination) }\end{array}$ & $\begin{array}{c}\text { Persistent gait disturbance } \\
\text { persisted during follow up (\%) }\end{array}$ & $\begin{array}{c}\text { Persistent gait disturbance not } \\
\text { developed during follow up (\%) }\end{array}$ \\
\hline Positive & $10(77)$ & $9(26)$ & 19 \\
Negative & $3(23)$ & $25(74)$ & 28 \\
Total & 13 & 34 & Total \\
\hline
\end{tabular}

$\mathrm{P}=0.0026$, MOG: Myelin oligodendrocyte glycoprotein

\section{Table 6: Distribution of persistent MOG positivity with development of MS}

\begin{tabular}{lcc}
$\begin{array}{l}\text { MOG titer (6 months after } \mathbf{1}^{\text {st }} \\
\text { episode of demyelination) }\end{array}$ & $\begin{array}{c}\text { MS developed } \\
\text { during follow-up (\%) }\end{array}$ & $\begin{array}{c}\text { MS not developed } \\
\text { during follow-up (\%) }\end{array}$ \\
\hline Positive & $1(33)$ & $18(41)$ \\
Negative & $2(67)$ & $26(59)$ \\
Total & 3 & 44
\end{tabular}

$\mathrm{P}=1.000, \mathrm{MOG}$ : Myelin oligodendrocyte glycoprotein, MS: Multiple sclerosis

titers or persistence of MOG antibody can predict the need for long-term therapy. ${ }^{31}$ Hence, further large-scale studies are required for demonstration of any benefit of considering early initiation of immunomodulating drugs such as rituximab, mycophenolate mofetil, azathioprine to reduction of recurrence in pediatric ADEM with persistently positive MOG antibody. Since persistent positivity to MOG indicates a recurrent course, serial testing should also be recommended. In a study published in 2017 regarding promising outcome for the use of MOG antibodies as prognostic biomarkers showing conversion to seronegative during immune-directed therapies. The conversion was found to be a positive predictive marker for disease-free activity in the subsequent period. ${ }^{32}$ Due to the significant role of MOG antibody, serial antibody testing should be included in an algorithm for follow-up of children with ADEM in clinical practice except in cases of typical MS. Further largescale prospective studies on longitudinal analysis of antibodies are required to enable the development of evidence-based treatment strategies and assess the possible correlation of MOG Antibody titers with disease activity.

\section{Limitations of the study}

The duration of follow-up in our study was relatively short (1 year).MDEM may developed after 1 year of first attack of ADEM. Furthermore,MOG antibody titer may fluctuate over a prolong time interval. Probably long duration followup study with sequential monitoring of MOG antibody would be more conclusive.

\section{CONCLUSION}

Persistently positive MOG Antibody was significantly associated with the development of MDEM, epilepsy, persistent gait disturbance, and steroid dependency. Further studies are required for the demonstration of benefits of considering early initiation of immunomodulating drugs in reduction of recurrence in pediatric ADEM with persistently positive MOG antibody.

\section{ACKNOWLEDGMENT}

Nil

\section{REFERENCES}

1. Absoud M, Cummins C, Chong WK, De Goede C, Foster K and Gunny R. Pediatric UK demyelinating disease longitudinal study (PUDDLS) BMC Pediatr. 2011;11:68.

https://doi.org/10.1186/1471-2431-11-68

2. Gulati S, Chakrabarty B, Kumar A, Jain P, Patel H and Sani L. Acquired demyelinating disorders of central nervous system: A pediatric cohort. Ann Indian Acad Neurol. 2015;18(Suppl 1):S48-S55.

https://doi.org/10.4103/0972-2327.164829

3. Dekate PS. Acquired demyelinating disorders of central nervous system. Indian J Child Health. 2014;1:128-135.

4. Leake JA, Albani S, Kao AS, Senac MO, Billman GF, Nespeca MP, et al. Acute disseminated encephalomyelitis in childhood: Epidemiologic, clinical and laboratory features. Pediatr Infect Dis J. 2004;23(8):756-764. 
https://doi.org/10.1097/01.inf.0000133048.75452.dd

5. Banwell B, Kennedy J, Sadovnick D, Arnold DL, Magalhaes S, Wambera K, et al. Incidence of acquired demyelination of the CNS in Canadian children. Neurology. 2009;72(3):232-239. https://doi.org/10.1212/01.wnl.0000339482.84392.bd

6. Tenembaum S, Chitnis T, Ness J, Hahn JS and International Pediatric MS Study Group. Acute disseminated encephalomyelitis. Neurology. 2007;68(16 Suppl 2):S23-S36. https://doi.org/10.1212/01.wnl.0000259404.51352.7f

7. Chabas $D$ and Waubant EL. Demyelinating Disorders of the Central Nervous System in Childhood. Cambridge, UK: Cambridge University Press; 2011.

8. Kariyawasam S, Singh RR, Gadian J, Lumsden DE, Lin JP, Siddiqui $A$, et al. Clinical and radiological features of recurrent demyelination following acute disseminated encephalomyelitis (ADEM). Mult Scler Relat Disord. 2015;4(5):451-456. https://doi.org/10.1016/j.msard.2015.06.013

9. Dale RC, de Sousa Chong WK, Cox TC, Harding B, Neville BG. Acute disseminated encephalomyelitis, multiphasic disseminated encephalomyelitis and multiple sclerosis in children. Brain. 2000;123(12):2407-2422.

https://doi.org/10.1093/brain/123.12.2407

10. Hacohen Y, Mankad K, Chong WK, Barkhof F, Vincent A, Lim M, et al. Diagnostic algorithm for relapsing acquired demyelinating syndromes in children. Neurology. 2017;89(3):269-278.

https://doi.org/10.1212/WNL.0000000000004117

11. Baumann M, Hennes EM, Schanda K, Karenfort M, Kornek B, Seidl R, et al. Children with multiphasic disseminated encephalomyelitis and antibodies to the myelin oligodendrocyte glycoprotein (MOG): Extending the spectrum of MOG antibody positive diseases. Mult Scler. 2016;22(14):1821-1829. https://doi.org/10.1177/1352458516631038

12. Hacohen $Y$, Wong $Y Y$, Lechner $C$, Jurynczyk M, Wright $S$, Konuskan B, et al. Disease course and treatment responses in children with relapsing myelin oligodendrocyte glycoprotein antibody associated disease. JAMA Neurol. 2018;75(4):478-487.

https://doi.org/10.1001/jamaneurol.2017.4601

13. Ramanathan S, Mohammad S, Tantsis E, Nguyen TK, Merheb V, Fung VS, et al. Clinical course, therapeutic responses and outcomes in relapsing MOG antibody-associated demyelination. J Neurol Neurosurg Psychiatry. 2018;89(2):127-137. https://doi.org/10.1136/jnnp-2017-316880

14. Brilot F, Dale RC, Selter RC, Grummel V, Kalluri SR, Aslam M, et al. Antibodies to native myelin oligodendrocyte glycoprotein in children with inflammatory demyelinating central nervous system disease. Ann Neurol. 2009;66(6):833-842.

https://doi.org/10.1002/ana.21916

15. McLaughlin KA, Chitnis T, Newcombe J, Franz B, Kennedy J, McArdel S, et al. Age-dependent B cell autoimmunity to a myelin surface antigen in pediatric multiple sclerosis. J Immunol. 2009;183(6):4067-4076.

https://doi.org/10.4049/jimmunol.0801888

16. Hacohen $\mathrm{Y}$, Absoud M, Deiva K, Franz B, Kennedy J, McArdel S, et al. Myelin oligodendrocyte glycoprotein antibodies are associated with a non-MS course in children. Neurol Neuroimmunol Neuroinflamm. 2015;2(2):e81. https://doi.org/10.1212/NXI.0000000000000081

17. Konuskan B, Yildirim M, Gocmen R Okur TD, Polat I, Kilic H, et al Retrospective analysis of children with myelin oligodendrocyte glycoprotein antibodyrelated disorders. Mult Scler Relat Disord. 2018;26:1-7. https://doi.org/10.1016/j.msard.2018.07.022

18. Reindl $M$ and Waters $P$. Myelin oligodendrocyte glycoprotein antibodies in neurological disease. Nat Rev Neurol. 2019;15(2):89-102. https://doi.org/10.1038/s41582-018-0112-x

19. Dale RC, Tantsis EM, Merheb V, Kumaran RY, Sinmaz N, Pathmanandavel K, etal. Antibodies to MOG have a demyelination phenotype and affect oligodendrocyte cytoskeleton. Neurol Neuroimmunol Neuroinflamm. 2014;1(1):e12.

20. Johns TG and Bernard CC. The structure and function of myelin oligodendrocyte glycoprotein. J Neurochem. 1999;72(1):1-9. https://doi.org/10.1046/j.1471-4159.1999.0720001.x

21. Reindl M and Rostasy K. MOG antibody-associated diseases. Neurol Neuroimmunol Neuroinflamm. 2015;2(1):e60. https://doi.org/10.1212/NXI.0000000000000060

22. Di Pauli F, Reindl M and Berger T. New clinical implications of anti-myelin oligodendrocyte glycoprotein antibodies in children with CNS demyelinating diseases. Mult Scler Relat Disord. 2018;22:35-37. https://doi.org/10.1016/j.msard.2018.02.023

23. Krupp LB, Tardieu M, Amato MP, Banwell B, Chitnis T, Dale RC, et al. International Pediatric Multiple Sclerosis Study Group. International pediatric multiple sclerosis study group criteria for pediatric multiple sclerosis and immune-mediated central nervous system demyelinating disorders: Revisions to the 2007 definitions. Mult Scler. 2013;19(10):1261-1267.

https://doi.org/10.1177/1352458513484547

24. Alexander M, and Murthy JM. Acute disseminated encephalomyelitis: Treatment guidelines. Ann Indian Acad Neurol. 2011;14(Suppl 1):S60-S64. https://doi.org/10.4103/0972-2327.83095

25. Reindl M, Di Pauli F, Rostasy K and Berger T. The spectrum of MOG autoantibody-associated demyelinating diseases. Nat Rev Neurol. 2013;9(8):455-461.

https://doi.org/10.1038/nrneurol.2013.118

26. Hennes EM, Baumann M, Lechner C and Rostasy K. MOG spectrum disorders and role of MOG-antibodies in clinical practice. Neuropediatrics. 2018;49(1):3-11. https://doi.org/10.1055/s-0037-1604404

27. Mikaeloff $Y$, Caridade G, Husson B, Suissa S, Tardieu M and Neuropediatric KIDSEP Study Group of the French Neuropediatric Society. Acute disseminated encephalomyelitis cohort study: Prognostic factors for relapse. Eur J Paediatr Neurol. 2007;11(2):90-95.

https://doi.org/10.1016/j.ejpn.2006.11.007

28. Cohen O, Steiner-Birmanns B, Biran I, Abramsky O, Honigman $S$ and Steiner I. Recurrence of acute disseminated encephalomyelitis at the previously affected brain site. Arch Neurol. 2001;58(5):797-801. https://doi.org/10.1001/archneur.58.5.797

29. Hacohen $Y$ and Banwell B. Treatment approaches for MOG-Abassociated demyelination in children. Curr Treat Options Neurol. 2019;21(1):2. https://doi.org/10.1007/s11940-019-0541-x

30. Cobo-Calvo A, Ruiz A, Maillart E, Audoin B, Zephir H, Bourre B, et al. Clinical spectrum and prognostic value of CNS MOG autoimmunity in adults: The MOGADOR study. Neurology. 2018;90(21):e1858-e1869.

https://doi.org/10.1212/WNL.0000000000005560

31. Dos Passos GR, Oliveira LM, da Costa BK, ApostolosPereira SL, Callegaro D, Fujihara K, et al. MOG-IgG-associated optic neuritis, encephalitis, and myelitis: Lessons learned 
from neuromyelitis optica spectrum disorder. Front Neurol. 2018;9:217.

https://doi.org/10.3389/fneur.2018.00217

32. Hyun JW, Woodhall MR, Kim SH, Jeong IH, Kong B, Kim G, et al.
Longitudinal analysis of myelin oligodendrocyte glycoprotein antibodies in CNS inflammatory diseases. J Neurol Neurosurg Psychiatry. 2017;88(10):811-817.

https://doi.org/10.1136/jnnp-2017-315998

\section{Authors Contribution:}

AB- Concept and design of the study, prepared first draft of manuscript, Interpreted the results; reviewed the literature and manuscript preparation;

MM- Concept, coordination, statistical analysis and interpretation, preparation of manuscript and revision of the manuscript

Work attributed to:

IQ City Medical College, West Bengal University of Health Sciences, Durgapur, West Bengal, India

Orcid ID:

Dr. Asish Banerjee - (D) https://orcid.org/0000-0002-7861-6732

Dr. Meenakshi Mitra - (iD https://orcid.org/0000-0002-8936-2205 